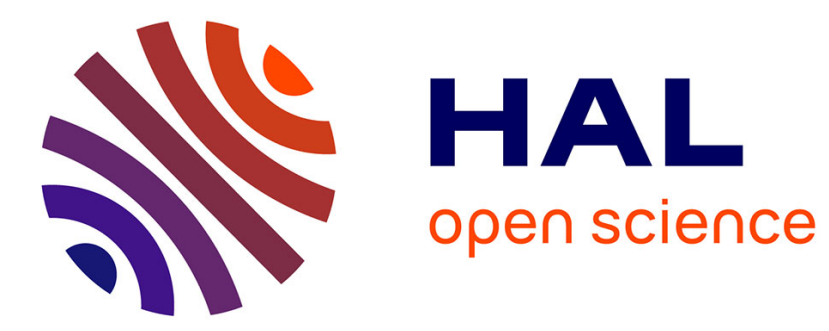

\title{
Matrix effects in secondary ion emission : quantitative analysis of silicates
}

\author{
A. Havette, G. Slodzian
}

\section{To cite this version:}

A. Havette, G. Slodzian. Matrix effects in secondary ion emission: quantitative analysis of silicates. Journal de Physique Lettres, 1980, 41 (10), pp.247-250. 10.1051/jphyslet:019800041010024700 jpa00231771

\section{HAL Id: jpa-00231771 https://hal.science/jpa-00231771}

Submitted on 1 Jan 1980

HAL is a multi-disciplinary open access archive for the deposit and dissemination of scientific research documents, whether they are published or not. The documents may come from teaching and research institutions in France or abroad, or from public or private research centers.
L'archive ouverte pluridisciplinaire HAL, est destinée au dépôt et à la diffusion de documents scientifiques de niveau recherche, publiés ou non, émanant des établissements d'enseignement et de recherche français ou étrangers, des laboratoires publics ou privés. 


\title{
Matrix effects in secondary ion emission : quantitative analysis of silicates
}

\author{
A. Havette and G. Slodzian $(*)$ \\ Laboratoire de Pétrographie-Volcanologie, Bât. 504 \\ (*) Laboratoire de Physique des Solides, Bât. 510, Université de Paris-Sud, 91405 Orsay, France.
}

(Reçu le 21 janvier 1980, accepté le 27 mars 1980)

\begin{abstract}
Résumé. - On montre que le rendement en ions secondaires positifs monoatomiques des minéraux silicatés est une fonction linéaire des concentrations cationiques. Cette loi ouvre la possibilité d'analyser quantitativement les minéraux et les verres silicatés dans des domaines pratiquement inaccessibles jusqu'ici : phases de petites dimensions (jusqu'à $0,5 \mu \mathrm{m})$ ou faibles concentrations $\left(5 \times 10^{-3}\right.$ à $\left.10^{-6}\right)$. Un modèle de rupture de liaison permet de comprendre l'origine de cette loi.
\end{abstract}

\begin{abstract}
In this paper we establish that the yield of secondary positive monoatomic ions of silicate targets is a linear function of the cationic concentrations. This law can be applied for quantitative analysis of silicates, minerals and glasses, in situations which were practically out of scope until now : small phases (down to $0.5 \mu \mathrm{m}$ ) or trace concentrations $\left(5 \times 10^{-3}\right.$ to $\left.10^{-6}\right)$. It represents a linear approximation which can be qualitatively understood by a bond breaking model.
\end{abstract}

1. Introduction. - Secondary ion emission of solid samples bombarded with a primary ion beam of a few kilo electron-volts' energy has been used extensively for obtaining local, elemental or isotopic compositions $[1,2,3]$. In many instances its development is still depending on the availability of appropriate quantitative analysis procedures. Difficulties are culminating in petrology because of the insulating nature of minerals [4], the high number of components and the presence of cluster ions.

In this paper, we propose a simple law which takes into account the influence that chemical composition exerts on the yield of monoatomic positive secondary ions. The parameters appearing in that law can be determined by means of experimental calibrations. Thus, precise quantitative analysis of a large class of minerals becomes attainable by secondary ion emission (SIMS).

2. Calibration procedure. - Let $\alpha$ be an index labelling a given mineral standard made of oxygen with a number $n$ of cations $\mathbf{M}_{j}$ whose cationic concentrations are represented by $C_{\alpha j}$. Emission of secondary $\mathrm{M}_{j}^{+}$ions produces a signal $I\left(\mathrm{M}_{j}\right)$ which depends on the density of the primary beam, the sputtering yield (average number of target atoms sputtered per incident ion) and the ionization yield $\tau\left(\mathbf{M}_{j}\right)$ (ratio of the average number of $\mathrm{M}_{j}^{+}$ions reaching the detector to the average number of $\mathbf{M}_{j}$ atoms which were composing the sputtered volume). In order to eliminate the influence of the primary beam density and that of the sputtering yield (which may vary from one mineral to another), it is convenient to refer the various emissions to that of a given component element $\mathbf{M}_{1}$ by taking signal ratios like $I\left(\mathrm{M}_{j}\right) / I\left(\mathbf{M}_{1}\right)$. Since our work is presently limited to silicates, the reference element $\mathbf{M}_{1}$ will be silicon. Thus we define a relative yield $r_{\alpha}$ for $\mathrm{M}_{j}[5]$ by the following expression :

$$
r_{\alpha}\left(\mathrm{M}_{j}\right)=\frac{I\left(\mathrm{M}_{j}\right)}{I\left(\mathrm{M}_{1}\right)} \cdot \frac{C_{\alpha 1}}{C_{\alpha j}}=\frac{\tau\left(\mathrm{M}_{j}\right)}{\tau\left(\mathrm{M}_{1}\right)} .
$$

On the table herein, each value of $r_{\alpha}(\mathrm{Al})$ has been reported together with the cationic composition of the standard on which the measurements were performed. The results shown in the table (as well as results not reported here for other elements) clearly show that the ionization yields vary with the standard's composition. In other words, a given element has no characteristic ionization yield. One consequence of this experimental fact, among others, is that one has to find what relationship exists between composition and ionization yields if one wishes to determine the composition of an unknown sample. This problem has been approached on an empirical basis, looking for simple phenomenological relations. The simplest was to try a linear relation as it had been already proposed [6] in a somewhat different context :

$$
\tau_{\alpha}\left(\mathbf{M}_{j}\right)=\sum_{l=1}^{n} k_{j l} C_{\alpha l}
$$


Table I. - Each line refers to a standard mineral characterized by its cationic composition expressed in $\%$. The relative yields $R_{\alpha}$ calculated with the coefficients $X_{j l}$ reported on the last line are compared to the measured yields $r_{\alpha}$; the index $\alpha$ stands for a given standard.

\begin{tabular}{|c|c|c|c|c|c|c|c|c|c|c|c|c|}
\hline Standard $c \%$ & Si & Al & $\mathrm{Na}$ & $\mathbf{K}$ & $\mathrm{Ca}$ & Mg & $\mathrm{Fe}^{2+}$ & $\mathrm{Fe}^{3+}$ & $\mathbf{T i}$ & $\begin{array}{c}r_{\alpha} \\
\text { mes. }\end{array}$ & $\begin{array}{l}\mathbf{R}_{\alpha} \\
\text { calc. }\end{array}$ & $\frac{r_{\alpha}-R_{\alpha}}{r_{\alpha}} \%$ \\
\hline glass & 69.2 & I5.I & 6.2 & 4.8 & $I .3$ & .8 & .5 & 0 & .2 & 4.07 & 4.05 & -.5 \\
\hline glass & 68.4 & I4.5 & 9.3 & 5.3 & .4 & 0 & $2 . I$ & 0 & $0^{\circ}$ & 4.29 & 4.39 & 2.3 \\
\hline albite & 60.1 & 20.2 & 19.7 & 0 & 0 & 0 & 0 & 0 & 0 & 4.42 & 4.49 & I. 6 \\
\hline leucite & 51.0 & 24.8 & 0 & 24.2 & 0 & 0 & 0 & 0 & 0 & 4.45 & $4.6 I$ & 3.6 \\
\hline oligoclase & 55.0 & $25 . I$ & 13.5 & I.I & 5.0 & 0 & .3 & 0 & 0 & 4.46 & 4.70 & 5.4 \\
\hline sanidine & 59.8 & 20.4 & 5.3 & I4. 5 & 0 & 0 & 0 & 0 & 0 & $4.5 I$ & 4.36 & -3.3 \\
\hline oligoclase & 56.3 & 24.0 & I5. 3 & I. 2 & 3.0 & 0 & 0 & 0 & 0 & $4.6 I$ & 4.60 & -.2 \\
\hline labradorite & 45.7 & 33.5 & 6.6 & 0 & I3.5 & 0 & 0 & 0 & 0 & 4.78 & 4.94 & 3.3 \\
\hline glass & 70.1 & IO. 6 & 9.0 & 5.6 & 0 & 0 & 4.6 & 0 & 0 & 4.82 & 4.67 & -3.2 \\
\hline glass & 68.4 & I0. 5 & IO. 6 & 5.3 & .3 & 0 & 3.0 & I. 6 & 0 & 5.07 & 5.03 & -.8 \\
\hline bytownite & 42.7 & 37.0 & 2.9 & 0 & 16.7 & .2 & .5 & 0 & 0 & 5.09 & 5.16 & .1 .8 \\
\hline anorthite & $4 I .3$ & 38.7 & I. 3 & 0 & I8.7 & $0^{\circ}$ & 0 & 0 & 0 & 5.15 & 5.14 & -.3 \\
\hline kyanite & 33.3 & 66.7 & 0 & 0 & 0 & 0 & 0 & 0 & 0 & 5.24 & 5.17 & $-I .4$ \\
\hline cordierite & 43.7 & 35.2 &.$I$ & .2 & 0 & 9.2 & 9.0 & 0 & 0 & 5.87 & 6.02 & 2.6 \\
\hline glass & 45.5 & I5.9 & 5.3 & .3 & II. 8 & II. 6 & 8.2 & 0 & I. 2 & 6.36 & 6.57 & 3.3 \\
\hline glass & 46.6 & I5.4 & 5.7 & .7 & II. 3 & 9.7 & 8.2 & 0 & I. 8 & $6.5 I$ & 6.64 & 2.0 \\
\hline salite & 45.3 & 4.3 & 0 & 0 & 22.0 & 19.9 & 6.9 & 0 & I.7 & 6.87 & 6.75 & $-I .7$ \\
\hline melilite & 36.9 & $=2.9$ & 7.3 & 0 & 32.5 & 7.5 & 0 & 2.9 & .1 & 7.08 & 6.62 & -6.5 \\
\hline glass & 43.3 & I9.I & 0 & 0 & 25.0 & 0 & 0 & 12.5 & 0 & 8.89 & 9.10 & 2.4 \\
\hline fassaite & 34.5 & I4.8 & .4 & 0 & 23.8 & II. 3 & 0 & 10.8 & 2.2 & 9.82 & 9.49 & -3.4 \\
\hline sphene & $3 I .7$ & I. 3 & .7 & 0 & $3 I .3$ & 0 & I. 5 & 0 & 27.3 & 12.89 & I2.55 & -2.6 \\
\hline$x_{j \ell} \quad\left(M_{j}=A l\right)$ & 3.2 & 6.0 & 6.5 & 5.9 & 7.4 & 9.2 & I8 & 40 & 36 & & & \\
\hline
\end{tabular}

where $k_{j l}$ are coefficients which have to be determined by means of calibration on standards. Experimental results suggested to try one more approximation, i.e. to assume that $\mathrm{Si}^{+}$yields are fairly insensitive to chemical composition, which amounts to assume that $k_{11} \simeq k_{1 l}$, so that one gets the expression :

$$
r_{\alpha}\left(\mathbf{M}_{j}\right)=\sum_{l=1}^{n} X_{j l} C_{\alpha l}
$$

where $X_{j l}=k_{j l} / k_{11}$; let $r_{\alpha}\left(\mathrm{M}_{j}\right)$ be the measured yield given by (1) and $R_{\alpha}\left(\mathrm{M}_{j}\right)$ the calculated yield obtained from expression (3) when a set of $X_{j l}$ coefficients is available. For a given element $\mathbf{M}_{j}$ and a given set of $v$ standards one gets a number $v$ of simultaneous linear equations where $X_{j l}$ are the unknowns. Here, the peculiar point is that a solution set $\left\{X_{j l}\right\}$ has to be compatible with the fact that the number $v$ of equations is higher than the number $n$ of unknowns. By the method of the least squares one can reach such a solution. On the last line of the table one can find a solution set $\left\{X_{j l}\right\}$ obtained by applying the method of the least squares to the relative deviations $\left(R_{\alpha}-r_{\alpha}\right) / r_{\alpha}$; the last three columns allow one to compare the experimental and the calculated relative yields.

Observing the strong influence of iron or titanium on the ionization yield of aluminium one may wonder whether assuming that the emission of silicon ions is insensitive to composition is still an acceptable approximation. Indeed, on mafic silicates, of high iron content, it has been found that the silicon yield is a little depending on the iron concentration; the silicon yield is roughly represented by $k_{11}\left(1+0.2 C_{\mathrm{Fe}}\right)$. Therefore, the corrections concerning most of the standards listed in the table are negligible.

The experimental conditions (energy of the primary beam, electrical charging-up on insulating targets, ion drift, collection and filtering of secondary ions, ...) have been already reported [7] ; let us just mention that the primary beam is composed of $\mathrm{O}_{2}^{+}$ hitting the surface with an energy of $5.5 \mathrm{keV}$ and an incidence angle of about $60^{\circ}$. It should be pointed out that it is absolutely essential to master these conditions in order to be able to get reproducible and meaningful measurements.

3. Quantitative analysis. - When one knows the relative yields of the various elements composing a given sample, it is an easy task to compute cationic concentrations. For instance, the concentration of element $\mathbf{M}_{j}$ is given by :

$$
C_{j}=\frac{I\left(\mathrm{M}_{j}\right) / R\left(\mathrm{M}_{j}\right)}{\sum_{j=1}^{n} I\left(\mathrm{M}_{j}\right) / R\left(\mathrm{M}_{j}\right)}
$$

Since the relative yields are concentration dependent, an iteration procedure has to be used. To start with we take a first set of $R\left(\mathrm{M}_{j}\right)$ corresponding to a mean composition or to a reasonable guess. Then, equations (4) allow one to compute a first set of concentrations $\left\{C_{j}\right\}_{1}$. In the next step, this set is used to compute a new set $\left\{R\left(\mathbf{M}_{j}\right)\right\}_{1}$ of relative yields with the help of relations (3). And so on, each new set of relative yields leads to a new set of 
concentrations... In practice, a stationary set of concentrations is reached after a number of iteration steps which does not exceed ten.

4. Discussion. - Several questions rise concerning the linear relationship between ionization yield and concentrations. First, the proof of its experimental validity is not completely satisfactory since it is based upon measurements of relative yields with the assumption that the ionization yield of silicon remains nearly unchanged. At first sight, this latter approximation is not too bad but its degree of validity should be established directly by measuring ionizating yields. On the other hand, intensities of secondary ions and concentrations of standards are available with limited accuracies, so that the computed solution set $\left\{X_{j l}\right\}$ will present limited precision. This precision may also depend on the peculiar choice of standards. Indeed, if the sampling of the standards actually used does not cover large concentration ranges, or more precisely if some relations between concentrations are accidentally favoured, some $X_{j l}$ coefficients may exhibit large but correlated deviations without leading to significant discrepancies between calculated and measured relative yields. Thus, more experiments are necessary to refine the precision on a solution set $\left\{X_{j l}\right\}$ and to check the degree of validity of the linear approximation.

It may be noted that a simple model could account for such a linear behaviour. Let us assume that the ionization probability of a given $\mathbf{M}_{j}$ atom leaving the target is controlled by electronic exchanges occurring during the last collision before ejection. This probability would specifically depend on the couple of cations involved in the interaction : then $k_{j l}$ appears to be proportional to the probability of getting a $\mathbf{M}_{j}^{+}$ion after the interaction between $\mathbf{M}_{j}$ leaving the target and the $\mathbf{M}_{l}$ cation surrounded with oxygen; the oxygen environment plays an essential role in the overlap of orbitals controlling the electronic exchanges. Since the probability for a $\mathbf{M}_{j}$ atom for interacting with a $\mathbf{M}_{l}$ oxide group is proportional to $C_{l}, k_{j l} C_{l}$ gives the contribution of such interactions to the probability of producing a $\mathrm{M}_{j}^{+}$ion. Adding the contributions coming from other elements leads to relation (2).

It is known that superficial and bulk concentrations can be significantly different so that one may wonder which type of concentration should be used in expression (2). The model suggests that superficial concentrations should be used whereas experimental results show that expression (2) works with bulk concentrations. It therefore appears that the applicability of the model could be depending on the magnitude of the ratios between the two types of concentrations for a given sample; for silicates, the departure from unity could be small enough to remain undetected because of the present limitations on the experimental accuracies. Such speculations would have to be extended to experiments made on metallic alloys flooded with oxygen $[6,11]$ on which ionization yields obey the same type of law. Since binary alloys are much simpler to handle than multicomponent silicates, it should be possible to get material for an answer.

Another possibility has to be considered. Let us concentrate on the binary collisions which result in the ejection of surface cations and which take place between cations sitting at the surface and cations coming from the underlying bulk material. The sputtering yields of such surface cations must be proportional to their bulk concentrations since it is usually agreed that the composition of the sputtered material is the same as the bulk one even if surface and bulk concentrations are different (except when the steady state is not reached). Now, if we assume that the flux of particles hitting the surface atoms from underneath has nearly the same composition as the deep bulk, the probability of a collision between a given surface $\mathbf{M}_{j}$ cation and a $\mathbf{M}_{l}$ cation will be proportional to the bulk concentration $C_{l}$. Once more, we obtain expression (2). In so far as the collision sequences involved here are prevailing the present derivation of relation (2) could describe the behaviour being observed experimentally, within the limits of experimental accuracies, despite differencies that might occur between superficial and bulk concentrations.

Until now, we made the implicit assumption that the ejection of polyatomic clusters had no effect on the ionization yields. This approximation is justified as long as the ratios between the yields of polyatomic and monoatomic species are small or stay nearly constant when the samples are changed. On the other hand, if for all elements the corresponding ratios experienced the same fractional change when different samples are examined, that would remain undetected because we record relative yields only. Again, direct measurements of ionization yield would help to clarify the situation.

It should be recalled that the approach being developed here greatly differs from the phenomenological theory of local thermal equilibrium (LTE) which states the existence of a plasma localized in the impact area of the primary ion; temperature and electron density of this plasma are the ajustable parameters controlling the secondary ion yield $[8,9]$. Regardless the questionable physical bases of such a model, we think that the linear approximation here proposed should be able to yield more reliable and more precise results.

5. Conclusion. - From a practical point of view, the linear approximation for the relative yields allows one to achieve quantitative analysis of a large variety of silicates. Identification of small mineral phases (down to $0.5 \mu \mathrm{m}$ ) and quantitative reading of ion micrographs become possible in practice. Precise analysis of trace concentrations (from $10^{-2}$ 
to $10^{-6}$ ) will probably be one of the most interesting consequences in the near future.

The influence of the valence state of iron on aluminium yields came out rather unexpectedly. If such a result proved to be general, it could offer an alternative way for the determination of valence states when cationic concentrations are known by other means.

If the linear approximation were to be supported by further experimental evidence, it would be worth- while to get a deeper understanding of the simple model that we have suggested and, for instance, try a generalized Landau-Zener approach. Better knowledge of the evolution of $X_{j l}$ with the energy of the ejected particles and their direction of ejection would probably be helpful but this is a rather long term program. Anyway, the existence of this linear relation represents a contribution to our understanding of the fundamentals of secondary ion emission.

\section{References}

[1] Castaing, R. et Slodzian, G., C.R. Hebd. Séan. Acad. Sci. 255 (1962) 1893-1895

[2] Slodzian, G., Ann. Phys. 9 (1964) 591.

[3] Slodzian, G., Surf. Sci. 48 (1975) 161-186.

[4] Slodzian, G., Dennebouy, R. et Havette, A., XVIII Colloquium Spectroscopicum Internationale, Grenoble, 1975, II, p. $590-595$.

[5] Havette, A., Thèse 3e Cycle, Orsay (1974).

[6] Pivin, J. C., Roques-Carmes, C. et Slodzian, G., Int. J. Mass Spectrom. Ion Phys. 26 (1978) 219-235.
[7] Slodzian, G. et Havetre, A., J. Microsc. Spectrosc. Electron. 2 (1977) 81-85.

[8] Andersen, C. A., N.B.S. Spec. Publ. 427 (1975) 79-119.

[9] Lovering, J. F., N.B.S. Spec. Publ. 427 (1975) 135-178.

[10] Nixitin, E. E., Chemische Elementarprozesse, ed. H. Hartmann, (Springer Verlag, Heidelberg) 1968, p. 43-77.

[11] Roques-Carmes, C., Pivin, J. C. and Slodzian, G., Proceedings of the Second Int. Conf. (SIMS II) p. 160, Chemical Physics 9 (Springer Verlag), 1979. 